\title{
PENILAIAN RISIKO, ESTIMASI INTERVAL INSPEKSI, DAN METODE INSPEKSI PADA HYDROCARBON PIPING MENGGUNAKAN METODE RISK BASED INSPECTION (RBI)
}

\author{
Putri Ratnasari ${ }^{\star}$, Judi Alhilman, Aji Pamoso \\ Program Studi Teknik Industri, Fakultas Rekayasa Industri, Universitas Telkom \\ Email: putriratnasari897@gmail.com; judi.alhilman@telkomuniversity.ac.id; \\ aji_p9juli@yahoo.com
}

Artikel masuk : 31-07-2019

Artikel direvisi : 22-09-2019

Artikel diterima : 22-10-2019

*Penulis Korespondensi

\begin{abstract}
Abstrak - Piping adalah sistem perpipaan yang digunakan untuk mengalirkan fluida dari satu proses ke proses lainnya. Jenis piping yang diteliti adalah Hydrocarbon Piping yaitu sebagai penyalur fluida antara reaktor, regenerator, dan main column pada proses catalytic cracking. Fluida yang mengalir pada Hydrocarbon Piping dapat menyebabkan korosi dan mengakibatkan terjadinya penipisan bahkan kebocoran pipa sehingga menimbulkan dampak yang buruk, baik pada lingkungan, keamanan, keselamatan, dan kerugian biaya. Peralatan bertekanan seperti piping memerlukan program inspeksi agar dapat bekerja dengan baik. Risk Based Inspection (RBI) adalah suatu metode untuk menentukan rencana program inspeksi berdasarkan risiko kegagalan peralatan. Metode RBI yang digunakan adalah RBI Semi-Kuantitatif dengan standar API 581. Tujuan penelitian ini adalah untuk mengetahui tingkatan risiko, estimasi interval inspeksi, dan penentuan metode inspeksi pada piping. Dari hasil penelitian menunjukkan bahwa Hydrocarbon Piping terdiri dari $16 \%$ pipa dengan tingkat risiko low dan $84 \%$ pipa dengan tingkat risiko medium. Estimasi interval inspeksi dianjurkan tidak melebihi setengah remaining life pipa. Dengan mekanisme kerusakan thinning, metode inspeksi yang dianjurkan ialah profile radiography, UT scans, dan visual examination.
\end{abstract}

Kata kunci: Interval Inspeksi; Piping; Remaining Life; Risk Based Inspection; Tingkat Risiko

\begin{abstract}
Piping is a piping system used to drain fluid from one process to another. The piping type of tubing studied is Hydrocarbon Piping as a fluid distributor between the reactor, regenerator, and main column in the catalytic cracking process. Flowing fluid on the Hydrocarbon Piping can cause corrosion and cause thinning and even leakage of pipes, harming the environment, security, safety, and loss of costs. Pressurized equipment such as piping requires an inspection program to work correctly. RiskBased Inspection (RBI) is a method for determining inspection program plans based on the risk of equipment failure. The RBI method used is Semi-Quantitative RBI with API 581. The purpose of this study is to determine the level of risk, estimation of inspection intervals, and determination of piping inspection methods. The results of the study show that Hydrocarbon Piping consists of $16 \%$ pipes with low-risk levels and $84 \%$ pipe with a medium risk level. Estimated inspection intervals are recommended not to exceed half the remaining life of the tube. With the mechanism of thinning damage, the recommended inspection method is profiled radiography, UT scans, and visual examination.
\end{abstract}

Keywords: Inspection Interval; Level of Risk; Piping; Remaining Life; Risk Based Inspection 


\section{PENDAHULUAN}

PT. XYZ merupakan salah satu unit perusahaan pengolah minyak bumi dan gas yang menghasilkan produk BBM, produk non-BBM, dan produk petrokimia. PT. XYZ perlu memastikan dalam proses pengolahannya tidak terjadi kegagalan proses. Kegagalan proses dapat berupa kerusakan atau kebocoran sistem perpipaan pada kilang yang bisa berdampak pada kecelakaan maupun ledakan karena pipa mengandung gasgas eksplosif (Dwiyanti \& Pradana, 2013). Sistem perpipaan digunakan untuk mengalirkan fluida dari satu proses ke proses lainnya disebut dengan piping.

Pada prosesnya pemeliharaan sistem perpipaan memerlukan penanganan tersendiri karena sistem kebocoran yang tidak mudah diidentifikasi. Berdasarkan data perusahaan selama tahun 2015 sampai tahun 2018 terdapat 96 titik kebocoran dengan tingkat kebocoran tertinggi pada unit A sebanyak 82 kebocoran (Gambar 1). Unit A merupakan unit inti dari kilang karena proses utama yaitu proses catalytic cracking terjadi di unit tersebut. Hydrocarbon Piping memiliki peranan penting sebagai penyalur antara reaktor, regenerator, dan main column pada proses tersebut di Unit A. Fluida panas beserta kandungan sulfur dan nitrogen yang merupakan impurities dari katalis mengalir di dalam Hydrocarbon Piping. Fluida tersebut dapat menyebabkan korosi dan mengakibatkan terjadinya penipisan bahkan kebocoran pada Hydrocarbon Piping. Kebocoran pipa dapat menimbulkan dampak buruk yang mempengaruhi lingkungan, keamanan, keselamatan, dan kerugian biaya. Oleh karena itu, perlu adanya langkah preventif berupa perawatan pada Hydrocarbon Piping untuk menghindari kecelakaan.

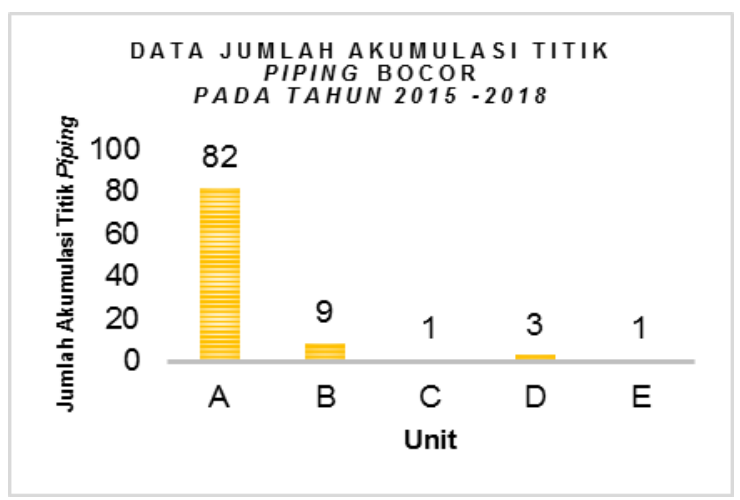

Gambar 1. Data Jumlah Akumulasi Titik Piping yang Bocor pada Tahun $2015-2018$

Suatu peralatan ataupun mesin memerlukan sistem perawatan terencana karena semakin lama peralatan digunakan, maka lifetime peralatan semakin tinggi dan semakin meningkat tingkat bahaya yang terjadi (Alhilman, Saedudin, Atmaji, \& Suryabrata, 2015). Perawatan adalah kegiatan yang dilakukan untuk memastikan bahwa komponen atau sistem dapat digunakan sesuai dengan fungsinya (Saedudin, Alhilman, Tatas, \& Atmaji, 2015). Perawatan tersebut dapat dilakukan dengan analisis lanjut mengenai laju korosi, umur sisa, dan tingkat risiko sehingga dapat diestimasikan program rencana inspeksi pipa yang lebih terarah.

Risk Based Inspection (RBI) adalah metode untuk menentukan program atau rencana inspeksi berdasarkan risiko kegagalan dan akibat/ konsekuensi kegagalan suatu peralatan (Chang, Chang, Shu, \& Lin, 2005; Prasetiyo \& Priyanta, 2015; Tan, Li, Wu, Zheng, \& He, 2011). Risiko RBI didefinisikan sebagai hasil kombinasi antara probability of failure dengan consequence of failure. RBI dapat mengklasifikasikan yang berisiko tinggi, sedang dan rendah, dan kemudian memfokuskan pemeriksaan pada risiko tinggi (Dou et al., 2017). Proses perencanaan RBI terdiri dari interval dan cakupan pemeriksaan yang fleksibel (yaitu metode atau prosedur untuk pemeriksaan) yang didasarkan pada penilaian risiko dan telah diterapkan secara luas di industriindustri (Washer, Connor, Massoud Nasrollahi, \& Rebecca Reising, 2016). Seperti Dou et al., (2017), menggunakan pressure vessel dan pipeline dalam proses pencairan batubara untuk menentukan tingkat resiko peralatan dan perencanaan inspeksi berupa penjadwalan inspeksi dan skema inspeksi dengan RBI sesuai American Petroleum Institute 581 atau API 581 (Dou et al., 2017). Selain itu, Zhang et al. (2017) mengklasifikasikan tingkat resiko pada gas compressor station dengan RBI untuk mengetahui equipment apa saja yang perlu segera dilakukan inspeksi selanjutnya atau tindakan yang dapat mengurangi kemungkinan resiko (Zhang et al., 2017).

Berdasarkan pemaparan pendahuluan pada penelitian ini, maka metode $\mathrm{RBI}$ tepat digunakan karena Hydrocarbon Piping termasuk ke dalam jangkauan peralatan RBI menurut API 581 dan diharapkan analisis dari output RBI seperti tingkatan risiko peralatan, program interval inspeksi peralatan yang tepat, dan metode inspeksi yang sesuai berguna bagi perusahaan dalam melakukan pencegahan terjadinya dampak berbahaya pada Hydrocarbon Piping.

\section{METODE PENELITIAN}

Tahap awal penelitian dimulai dengan melakukan pengumpulan data yang diperlukan dalam pelaksanaan penelitian berupa data untuk 
penentuan remaining life, probability of failure, dan consequences of failure.

Tahap kedua adalah menentukan nilai minimum allowable thickness, corrosion rate, dan remaining life. Dengan mengetahui corrosion rate dan remaining life maka dapat diprediksi interval inspeksi yang akan dilakukan.

1. Minimum Allowable Thickness

Minimum Allowable Thickness atau $t_{\text {required }}$ merupakan batas tebal minimum suatu pipa untuk keamanan operasi (ASME International, 2015). Perhitungan Minimum Allowable Thickness pada pipa dapat dilihat pada persamaan. 1 (American Petroleum Institute, 2003b) .

$$
t=\frac{P D}{2(S E W+P Y)}
$$

Keterangan:

$$
\begin{aligned}
& T \quad \text { : Minimum Allowable Thickness (mm) } \\
& P \text { : Tekanan operasi maksimum (MPa atau } \\
& \mathrm{kg} / \mathrm{cm}^{2} \text { ) } \\
& D \quad \text { : Diameter luar pipa }(\mathrm{mm}) \\
& S \quad \text { : Kekuatan material pipa (MPa atau } \\
& \mathrm{kg} / \mathrm{cm}^{2} \text { ) } \\
& \text { E : Joint efficiency } \\
& W \quad: \text { Weld joint strength reduction factor } \\
& Y \quad \text { : Coefficient }
\end{aligned}
$$

\section{Corrosion Rate $(C R)$}

Perhitungan corrosion rate pada pipa dapat dilihat pada persamaan 2 (American Petroleum Institute, 2003a).

$$
C R=\frac{t_{\text {initial }}-t_{\text {actual }}}{\text { time }(\text { years }) \text { between } t_{\text {initial }} \text { and } t_{\text {actual }}}
$$

\section{Remaining Life $(R L)$}

Remaining life ialah waktu dari pipa mencapai batas minimum ketebalannya ( $\left.t_{\text {required }}\right)$ (American Petroleum Institute, 2003a).

$$
R L=\frac{t_{\text {actual }}-t_{\text {required }}}{\text { corrosion rate }[\text { inches }(\mathrm{mm}) \text { per year }]}
$$

Tahap ketiga adalah memproses data generic failure frequency, data damage factor, dan data faktor manajemen sistem pada Hydrocarbon Piping untuk melakukan perhitungan nilai probability of failure. Hasil perkalian tersebut dikonversi ke dalam probability of failure category. Selanjutnya, memproses data area-based consequence dan financial-based consequence untuk mengkonversi ke dalam masing - masing consequence of failure category.

\section{Probability of Failure}

Probability of failure secara universal merupakan fungsi waktu (s) dan meningkatnya kerusakan secara bertahap pada komponen yang terakumulasi dengan waktu (Dou et al., 2017). Probability of failure yang digunakan dalam API 581 dapat dilihat pada rumus 4 .

$P f(t) \quad=g f f \cdot D f(t) \cdot \mathrm{F}_{\mathrm{MS}}$

Dari persamaan 4, probability of failure diperoleh dari frekuensi kegagalan komponen (gff), faktor kerusakan $(D f(t))$, faktor manajemen sistem ( $F_{M S}$ ) (American Petroleum Institute, 2016). API 581 memberikan rentang kategori untuk probability of failure seperti yang dapat dilihat pada Tabel 1.

Tabel 1. Probability of Failure Category (American Petroleum Institute, 2016)

\begin{tabular}{cc}
\hline Category & Probability Range \\
\hline 1 & $P f \leq 3,06 \mathrm{E}-05$ \\
2 & $3,06 \mathrm{E}-05 \leq P f \leq 3,06 \mathrm{E}-04$ \\
3 & $3,06 \mathrm{E}-04 \leq P f \leq 3,06 \mathrm{E}-03$ \\
4 & $3,06 \mathrm{E}-03 \leq P f \leq 3,06 \mathrm{E}-02$ \\
5 & $P f \geq 3,06 \mathrm{E}-02$ \\
\hline
\end{tabular}

2. Consequence of Failure

Konsekuensi diartikan sebagai akibat yang ditimbulkan dari suatu kegagalan. Dalam API RBI, konsekuensi dari kegagalan, dianggap tidak bervariasi dengan waktu (Seo et al., 2015). Zhang et al. (2017) dalam penelitiannya, menggunakan dua aspek konsekuensi kegagalan, yaitu

\begin{tabular}{|c|c|c|}
\hline Category & $\begin{array}{c}\text { Area-Based } \\
\text { Consequence }\end{array}$ & $\begin{array}{c}\text { Financial- } \\
\text { Based } \\
\text { Consequence }\end{array}$ \\
\hline & Range $\left(\mathrm{m}^{2}\right)$ & Range (\$) \\
\hline A & $C A \leq 9,29$ & $F C \leq 10000$ \\
\hline $\mathrm{B}$ & $9,29 \leq C A \leq 92,9$ & $\begin{array}{c}10000 \leq F C \leq \\
100000\end{array}$ \\
\hline C & $92,9 \leq C A \leq 929$ & $\begin{array}{c}100000 \leq F C \leq \\
1000000\end{array}$ \\
\hline D & $929 \leq C A \leq 9290$ & $\begin{array}{c}1000000 \leq F C \leq \\
10000000\end{array}$ \\
\hline$E$ & $C A \geq 9290$ & $F C \geq 10000000$ \\
\hline
\end{tabular}
consequence of failure area (konsekuensi pembakaran, konsekuensi toksik, dan konsekuensi kebocoran media tidak beracun dan tidak mudah terbakar) dan consequence of economic loss (biaya maintenance atau replacement, biaya kerusakan peralatan lainnya, biaya personal injury, dan biaya clean-up environment) (Zhang et al., 2017).

\section{Tabel 2. Area and Financial Based Consequence} Category

(American Petroleum Institute, 2016) 
Tipe-tipe consequence of failure meliputi flammable/explosive, toxicity, environmental, dan business interruption serta hasil akhir dari tipe-tipe tersebut dalam menyajikan risiko terdiri dari business interruption (cost), equipment damage (area), health effects/safety (area), dan environmental impact (cost) (American Petroleum Institute, 2000). API 581 memberikan consequence of failure category berdasarkan area dan finansial (Tabel 2).

Tahap keempat adalah memplotkan probability of failure category dan consequence of failure category yang terpilih ke dalam risk matrix $\mathrm{RBI}$ dan menentukan tingkat resiko untuk mengetahui peralatan mana yang lebih diprioritaskan untuk dilakukan penanganan inspeksi sesuai dengan perencanaan interval inspeksi. Hasil perhitungan risiko diwakili dalam bentuk risk matrix. Penggunaan matriks risiko adalah cara yang sangat efektif untuk mengkomunikasikan output tanpa menggunakan nilai angka (Vianello, Milazzo, Guerrini, Mura, \& Maschio, 2016). Dalam risk matrix, kategori konsekuensi dan probabilitas disusun sedemikian rupa sehingga komponen risiko tertinggi mengarah ke sudut kanan atas (Gambar 2).
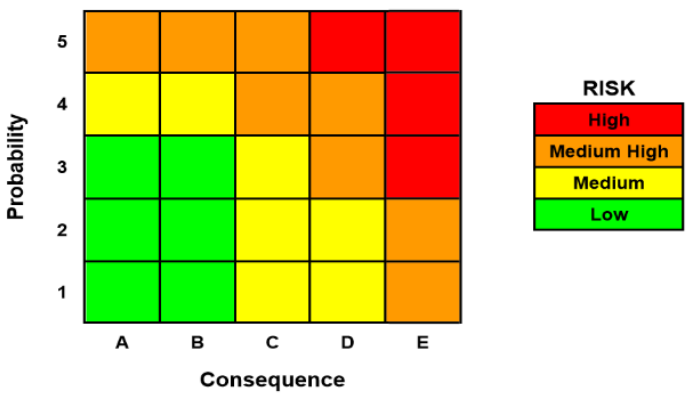

Gambar 2. Risk Matrix

(American Petroleum Institute, 2016)

Tahap kelima adalah menentukan interval inspeksi berdasarkan tingkat resiko dengan mempertimbangkan remaining life yang telah dihitung sebelumnya dan menentukan metode inspeksi yang tepat sesuai dengan damage factor yang terjadi pada Hydrocarbon Piping. Prabowo, Husodo dan Arumsari (2018) dalam menentukan interval inspeksi onshore pipeline menggunakan standar DNV Qualitative Interval dan API 570 (Prabowo et al., 2018). DNV Qualitative Interval ditentukan berdasarkan tingkat risiko $\mathrm{RBI}$ sedangkan API 570 ditentukan berdasarkan konsep half remaining life.

1. DNV Qualitative Interval

DNV menyediakan matriks DNV Qualitative Interval berdasarkan tingkat risikonya seperti yang dapat dilihat pada Gambar 3.

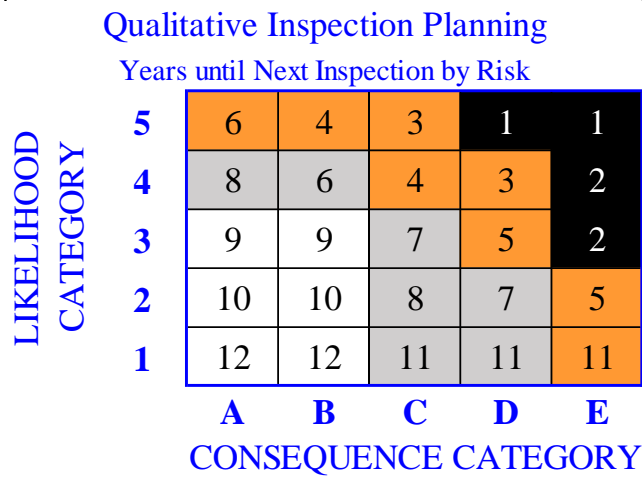

Gambar 3. DNV Qualitative Interval

(Prabowo et al., 2018)

2. Interval Inspeksi API 570

Inspeksi atau pengukuran ketebalan pipa dilakukan tidak melebihi setengah dari umur sisa pipa tersebut (American Petroleum Institute, 2003a). Penentuan interval inspeksi menggunakan konsep half remaining life yaitu dengan menjadwalkan interval inspeksi pada setengah remaining life.

\section{Metode Inspeksi}

Metode inspeksi merupakan metode yang tepat digunakan untuk mendeteksi mekanisme kerusakan pada peralatan (Qathafi, 2015). Prabowo, et, al (2018) menentukan metode inspeksi pada onshore pipeline berdasarkan API 581 sesuai damage factor dan kategori keefektifan inspeksi yang terjadi pada peralatan (Prabowo et al., 2018).

\section{HASIL DAN PEMBAHASAN}

Berikut penjelasan hasil perhitungan dan penentuan remaining life, tingkatan risiko, estimasi interval inspeksi, dan metode inspeksi untuk Hydrocarbon Piping yang berjumlah 108 line number pipa, di antaranya berukuran 0.75 , 1", 1.5", 2", 3", 4", 6", 8", 10", 12", 14", 24", 30", dan 40" dengan spesifikasi material carbon stee/ Gr B, carbon steel Gr B65, dan low alloy steel Gr P5.

\section{Generic Failure Frequency (gff)}

Ukuran semua line number pipa berdasarkan panduan API 581 memiliki nilai general failure frequency yang sama yaitu sebesar 3.06E-05 kegagalan/tahun. Nilai gff untuk Hydrocarbon Piping sebesar 3.06E-05 atau 0.0000306 kegagalan/tahun. Generic failures frequency merepresentasikan frekuensi kegagalan dari penurunan mutu kerja selama kegiatan operasional pada lingkungan yang spesifik. Semakin besar nilai generic failures frequency maka semakin besar pula probabilitas terjadinya kegagalan pada peralatan stasioner. 


\section{Damage Factor (Df)}

Mekanisme kerusakan yang terjadi pada Hydrocarbon Piping ialah thinning. Dalam menentukan thinning damage factor berdasarkan API 581 terdapat 15 tahapan. Dari 108 pipa yang telah ditentukan nilai Df-nya, terdapat dua pipa yang memiliki nilai $\mathrm{Df}$ terbesar yaitu pipe line number 101-PL0436-2 dan 101-PL0441-2 sebesar 45,23057. Tingginya nilai laju korosi yang dimiliki kedua pipa tersebut mempengaruhi besarnya nilai thinning damage factor. Semakin besar nilai thinning damage factor maka peluang terjadinya kegagalan pipa semakin besar.

\section{Faktor Manajemen Sistem ( $\left.F_{M S}\right)$}

Prosedur API 581 menggunakan alat evaluasi ini digunakan untuk menilai bagian dari fasilitas sistem manajemen yang berpengaruh terhadap kemungkinan kegagalan komponen. Evaluasi tersebut berupa pertanyaan-pertanyaan yang diajukan kepada bagian manajemen pabrik, operasional, inspeksi, pemeliharaan, engineering, training, dan keselamatan pekerja. Hasil evaluasi sistem manajemen PT. XYZ mendapatkan skor 879 dari 1000 dengan nilai pscore sebesar $88 \%$ dan nilai $\mathrm{F}_{\mathrm{MS}}$ sebesar 0,917107.

\section{Probability of Failure}

Berdasarkan perhitungan probability of failure pada Pers. (4) dan penentuan kategori sesuai Tabel 1, kategori utama untuk Hydrocarbon Piping ialah kategori 1. Di antara 108 pipa, terdapat 105 pipa di kategori 1, 1 pipa di kategori 2, dan 2 pipa di kategori 3 seperti dapat dilihat pada Gambar 4. Semakin besar nilai probability of failure maka semakin tinggi tingkat resiko yang diperoleh.

\section{Consequence of Failure}

Kategori dari setiap parameter consequence of failure yaitu, equipment damage area, safety area, business impact cost dan environment cost yang telah didapatkan kemudian dilakukan penentuan kategori consequence of failure sesuai Tabel 2. Tabel 3 merupakan contoh penentuan consequence of failure category pada salah satu line number pipa. Kategori utama untuk Hydrocarbon Piping ialah kategori C. Di antara 108 pipa, terdapat 17 pipa di kategori A, 74 pipa di kategori $C$, dan 17 pipa di kategori $D$ seperti dapat dilihat pada Gambar 5.

\section{Risk Matrix}

Berdasarkan hasil plotting pada Risk Matrix untuk Hydrocarbon Piping, dari 108 pipa terdapat 17 pipa berada pada low-risk level yang ditandai dengan kotak berwarna hijau dengan persentase $16 \%$ dan 91 pipa berada pada medium-risk level yang ditandai dengan kotak berwarna kuning dengan persentase $84 \%$. Untuk distribusi kategori risiko dan persentase tingkat risiko seluruh line number Hydrocarbon Piping secara detail dapat dilihat pada Gambar 6 dan Gambar 7. Pipa dengan low-risk level menandakan bahwa kegiatan inspeksi dan perawatan yang dilakukan PT. XYZ sudah baik untuk mengontrol risiko terjadinya kegagalan. Namun, tetap perlu adanya pencegahan atau tindakan mitigasi agar konsekuensi yang dihasilkan tidak menimbulkan dampak yang lebih besar. Pipa dengan mediumrisk leve/menunjukkan bahwa risiko tersebut perlu dikontrol agar tingkat risiko tidak naik menjadi medium-high-risk level bahkan high-risk level.

Tabel 3. CoF Category Hydrocarbon Piping (Line Number 101-PL0073-3/4)

\begin{tabular}{ccccc}
\hline $\begin{array}{c}\text { Equipment } \\
\text { Damage Area }\end{array}$ & $\begin{array}{c}\text { Safety } \\
\text { Area }\end{array}$ & $\begin{array}{c}\text { Business } \\
\text { Impact } \\
\text { Cost }\end{array}$ & $\begin{array}{c}\text { Environment } \\
\text { Cost }\end{array}$ & $\begin{array}{c}\text { CoF } \\
\text { Category }\end{array}$ \\
\hline A & A & B & C & C \\
\hline
\end{tabular}

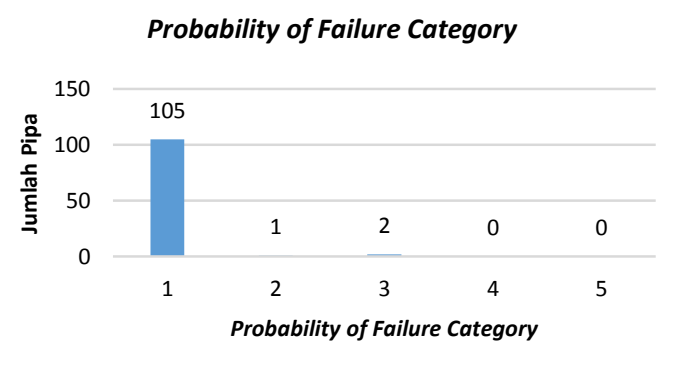

Gambar 4. Probability of Failure Category

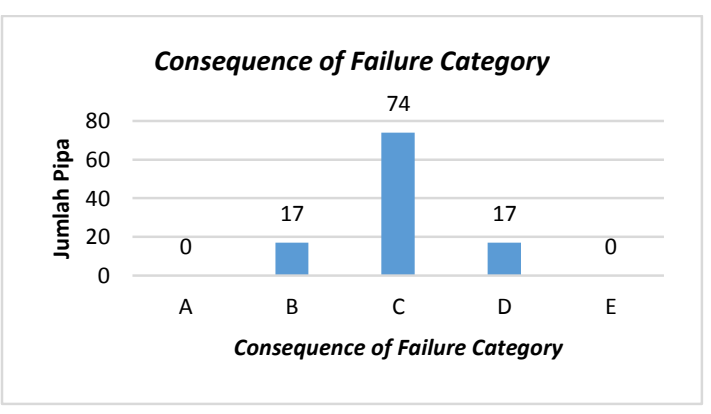

Gambar 5. Consequence of Failure Category

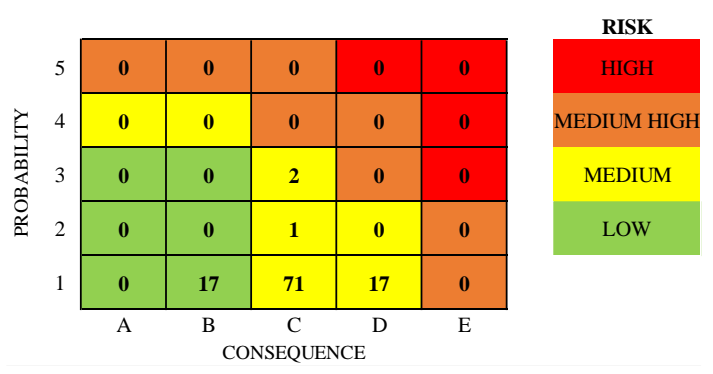

Gambar 6. Distribusi Risk Matrix 


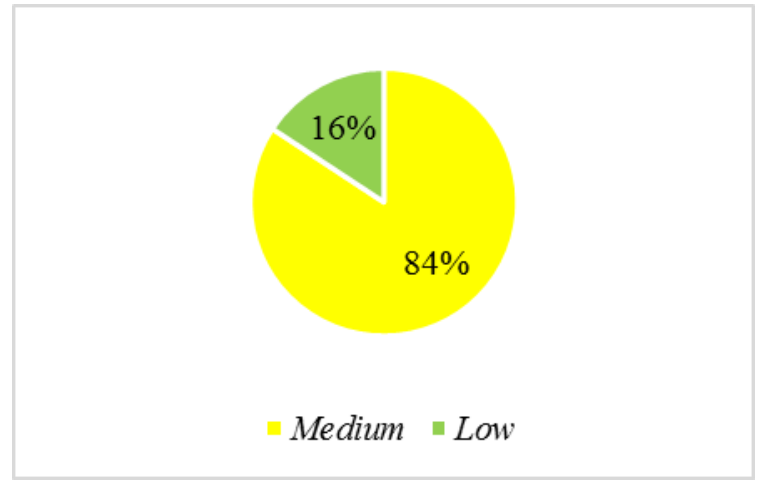

Gambar 7. Persentase Tingkat Risiko

\section{Corrosion Rate}

Nilai corrosion rate dapat mempengaruhi nilai remaining life suatu pipa. Semakin besar nilai corrosion rate maka nilai remaining life-nya semakin kecil. Setiap pipa memiliki corrosion rate yang berbeda-beda. Rentang corrosion rate yang terjadi pada Hydrocarbon Piping berkisar 0,1-1,68 $\mathrm{mm} /$ year. Berdasarkan hasil perhitungan corrosion rate seluruh line number Hydrocarbon Piping sesuai persamaan 2, diantara 108 pipa terdapat 2 pipa yang memiliki corrosion rate tertinggi yaitu pipe line number 101-PL0436-2 dan 101-PL0441-2. Hal tersebut dikarenakan kedua pipa memiliki nilai selisih antara nominal thickness dengan actual thickness paling besar selama tiga tahun pipa tersebut beroperasi. Berdasarkan hal tersebut, semakin besar selisih nominal thickness dengan actual thickness maka semakin besar pula corrosion rate suatu pipa.

\section{Remaining Life}

Berdasarkan hasil perhitungan remaining life Hydrocarbon Piping, setiap pipa memiliki hasil remaining life yang berbeda-beda. Hal ini dikarenakan corrosion rate yang dihasilkan tiap pipa berbeda. Selain itu, tekanan desain dan temperatur desain pada pipa juga menjadi faktor yang mempengaruhi remaining life pipa. Semakin besar tekanan desain dan temperatur desain pipa maka remaining life-nya semakin singkat. Dari 108 pipa, remaining life tersingkat ialah yaitu pipe line number 101-PL0436-2 dan 101-PL0441-2, dimana kedua pipa tersebut memiliki corrosion rate yang tertinggi.

\section{Interval Inspeksi}

Interval inspeksi merupakan interval waktu yang dibutuhkan untuk melakukan inspeksi selanjutnya. Untuk menentukan interval inspeksi masing-masing pipa menggunakan acuan $D N V$ Qualitative Interval berdasarkan kategori risiko yang diperoleh melalui risk matrix RBI. Penentuan interval inspeksi tersebut juga memperhatikan remaining life pipa di mana berdasarkan API 570, frekuensi inspeksi paling lama tidak melebihi setengah remaining life-nya. Hal tersebut dikarenakan apabila pipa melebihi setengah remaining life-nya, maka pipa tersebut membutuhkan penanganan lebih intensif dan analisa detail untuk memutuskan apakah pipa tersebut masih dapat digunakan untuk beroperasi atau perlu replacement dengan pipa baru.

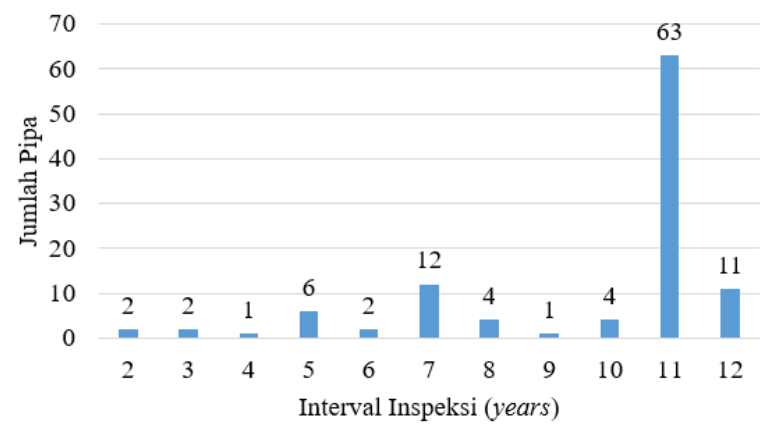

Gambar 8. Interval Inspeksi

Gambar 8 merupakan hasil interval inspeksi seluruh line number Hydrocarbon Piping. Pipa yang harus segera dilakukan inspeksi ialah pipa line number 101-PL0436-2 dan 101-PL0441-2 dengan penjadwalan inspeksi dua tahun ke depan karena kedua pipa tersebut memiliki remaining life yang paling singkat yaitu sebesar 3,82 tahun. Interval inspeksi tersebut harus dilakukan setelah inspeksi terakhir. Untuk inspeksi berikutnya, harus melakukan update pada perhitungan remaining life-nya karena kemungkinan terdapat perubahan ketebalan dinding pipa.

\section{Metode Inspeksi}

Metode inspeksi adalah suatu cara yang digunakan untuk mendeteksi kerusakan yang terjadi pada pipa yang diinspeksi dan bertujuan untuk menurunkan kemungkinan terjadinya risiko. Penentuan metode inspeksi mengacu pada API 581 dimana metode inspeksi ditentukan berdasarkan mekanisme kerusakan pipa dan kategori efektivitas inspeksi pipa sesuai tingkat risikonya.

Gambar 9 merupakan metode inspeksi yang tergolong efektif sesuai kondisi setiap pipa. Pipa yang mengalami localized corrosion menggunakan intrusive inspection berupa $>50 \%$ visual examination dan $100 \%$ tindak lanjut di daerah yang mengalami penipisan dari total luas permukaan pipa; 1 pipa yang mengalami localized corrosion menggunakan non-intrusive inspection berupa $>50 \%$ cakupan pada condition monitor location dengan ultrasonic scanning atau profile radiography; dan 104 pipa yang mengalami general corrosion menggunakan non-intrusive 
inspection berupa $>50 \%$ spot UT / random UT scans atau dapat juga menggunakan random profile radiography pada area terpilih dari total luas permukaan pipa. Metode-metode inspeksi yang digunakan termasuk jenis NDE (NonDestructive Examination) yaitu inspeksi yang dilakukan tanpa merusak benda ujinya.

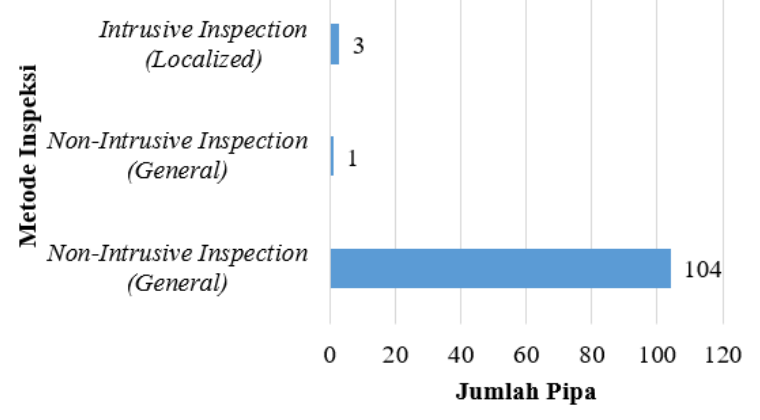

Gambar 9. Metode Inspeksi

\section{KESIMPULAN}

Berdasarkan dari hasil penelitian yang telah dilakukan, maka diperoleh hasil penilaian risiko RBI menunjukkan bahwa Hydrocarbon Piping memiliki $16 \%$ pipa yang berada pada low-risk level dan $84 \%$ pipa yang berada pada medium-risk level. Interval inspeksi Hydrocarbon Piping yang berbeda dipengaruhi oleh remaining life setiap pipa. Estimasi interval inspeksi Hydrocarbon Piping ditentukan berdasarkan tingkat risiko dan tidak melebihi setengah dari remaining life pipa. Berdasarkan mekanisme kerusakan dan tingkat risiko pada Hydrocarbon Piping, metode inspeksi yang dianjurkan ialah profile radiography, UT scans, dan visual examination. Penelitian ini dapat dilanjutkan pada pengembangan lebih dalam penerapan metode RBI untuk peralatan stasioner, seperti penggunaan sampel yang lebih banyak dalam mengevaluasi faktor manajemen sistem ( $\left.F_{M S}\right)$ agar hasil yang diperoleh lebih akurat.

\section{DAFTAR PUSTAKA}

Alhilman, J., Saedudin, R. R., Atmaji, F. T. D., \& Suryabrata, A. G. (2015). LCC application for estimating total maintenance crew and optimal age of BTS component. In 2015 3rd International Conference on Information and Communication Technology (IColCT) (pp. 543-547). IEEE.

American Petroleum Institute. (2000). API 581 RBI Base Resource Document.

American Petroleum Institute. (2003a). API 570 Piping Inspection Code.

American Petroleum Institute. (2003b). Basic Petroleum Data Book (Vol. 23). American Petroleum Institute.
American Petroleum Institute. (2016). API RP 581 Risk-based Inspection Methodology. Api 581 (Vol. Third Edit).

ASME International. (2015). ASME Code for Pressure Piping, B31 (Vol. 2014).

Chang, M.-K., Chang, R.-R., Shu, C.-M., \& Lin, K.N. (2005). Application of risk based inspection in refinery and processing piping. Journal of Loss Prevention in the Process Industries, 18(4-6), 397-402.

Dou, Z., Jiang, J. C., Wang, Z. R., Pan, X. H., Shu, C. M., \& Liu, L. F. (2017). Applications of RBI on leakage risk assessment of direct coal liquefaction process. Journal of Loss Prevention in the Process Industries, 45, 194-202. https://doi.org/10.1016/j.jp.2016.12.006

Dwiyanti, E., \& Pradana, R. K. (2013). Analisis Risiko Hydrogen Recovery Unit (Hru) dan Prioritas Risiko Kegagalan Komponen Pipa Gas Hidrogen di PT Petrokimia. Indonesian Journal of Occupational Safety and Health, 2(1), 10-19.

Prabowo, R. L., Husodo, A. W., \& Arumsari, N. (2018). Penilaian Risiko pada Onshore Pipeline Menggunakan Metode Risk Based Inspection ( $\mathrm{RBI}$ ). Proceeding 3rd Conference of Piping Engineering and Its Application, 3 No.1, 127-132.

Prasetiyo, G., \& Priyanta, D. (2015). Penilaian Risiko Dan Perencanaan Inspeksi Pada Sistem Perpipaan Menggunakan Metode Risk Based Inspection DNV-RP-G101. Jurnal ITS, 1-6.

Qathafi, M. Al. (2015). Studi Aplikasi Metode Risk Based Inspection (RBI) Semi-Kuantitatif API 581 Pada Production Separator, Skripsi, Institut Technology Sepuluh Nopember..

Saedudin, R. R., Alhilman, J., Tatas, F., \& Atmaji, D. (2015). Optimization of Preventive Maintenance Program and Total Site Crew for Base Transceiver Station ( Bts ) Using Reliability Centered Maintenance ( $\mathrm{Rcm}$ ) and Life Cycle Cost ( Lcc ) Method. International Seminar on Industrial Engineering and Management, 21-27.

Seo, J. K., Cui, Y., Mohd, M. H., Ha, Y. C., Kim, B. J., \& Paik, J. K. (2015). A risk-based inspection planning method for corroded subsea pipelines. Ocean Engineering, 109, 539-552.

https://doi.org/10.1016/j.oceaneng.2015.07. 066

Tan, Z., Li, J., Wu, Z., Zheng, J., \& He, W. (2011). An evaluation of maintenance strategy using risk based inspection. Safety Science, 49(6), 852-860.

Vianello, C., Milazzo, M. F., Guerrini, L., Mura, A., 
\& Maschio, G. (2016). A risk-based tool to support the inspection management in chemical plants. Journal of Loss Prevention in the Process Industries, 41, 154-168. https://doi.org/10.1016/j.jp.2016.03.005

Washer, G., Connor, R., Massoud Nasrollahi, \& Rebecca Reising. (2016). Verification of the Framework for Risk-Based Bridge Inspection. Journal of Bridge Engineering, 21(4), 04015078. https://doi.org/10.1061/(ASCE)BE.1943-

5592.0000787.

Zhang, M., Liang, W., Qiu, Z., \& Lin, Y. (2017). Application of Risk-Based Inspection method for gas compressor station. Journal of Physics: Conference Series, 842, 012064. https://doi.org/10.1088/1742-

$6596 / 842 / 1 / 012064$ 